\title{
Facades Planting: Contributing to a Better Environment; Empirical Study on -New Cairo District, Egypt
}

\author{
Indjy M. Shawket ${ }^{1}$ \\ ${ }^{1}$ Lecturer in Modern Academy, Architectural department, Egypt \\ Correspondence: Indjy Mohamed Shawket, Modern Academy, Egypt. E-mail: ng_mohamed@hotmail.com
}

Received: December 18, 2014 Accepted: January 8, 2015 Online Published: January 22, 2015

doi:10.5539/jsd.v8n1p24 URL: http://dx.doi.org/10.5539/jsd.v8n1p24

\begin{abstract}
Planting facades or balconies could be a simple short method of supporting urban development; it could be considered a first step and easy solution for deurbanized countries.

Most of the third world countries have internal problems that impact their whole environment, especially at the urban level.

Egypt is one of those countries that suffers from financial problems, and where government is not playing its role in supporting urbanization even in the new areas (e.g. New Cairo). However, Façade greenery (especially balconies) could be an easy step to start paying attention to urbanization as a new field (This could also encourage different subgroups e.g.: (apartment owners, government, civil organizations) to develop their facades in order to create a better urban environment.

That is why the researcher started to think about different alternatives through case-studies to find out the best method to achieve an easy to maintain cost-effective façade greenery within a short period of time.
\end{abstract}

Keywords: plantings, poor countries, facades, balconies, urban, living walls

\section{Introduction}

\subsection{Defining the Problem}

Third world countries suffer from de-urbanization; each of them has its own reasons for that. Egypt's weak economy forces the government to give a priority to creating primitive networks (roads and bridges) as they are the main focus, without taking into consideration any other urban elements such as the green arrangements (plan scale or elevation scale). On the other hand, apartment owners look after what is inside their units rather than the façades, where no determents to respect, nor a model to follow. Moreover, no sector is giving attention to the urban perspective, even in new cities, especially the facades. Facades are not only the major element of creating the identity of the place; people also feel any change to them and directly get affected by them.

Thus, facade planting is one of the important direct changes that could contribute to a better environment at different levels such as health, beauty, psychology, etc.

Greenery makes people feel full of life and it is beneficial for them to allay tiredness and enhance physical as well as mental well-being. (Ming Zhou, 2013, p. 2793).

\subsection{Defining Process to Solution}

Contributing to a better environment through façade planting is a primary objective, which could be done by researching some secondary objectives, highlighting the importance of plants in our lives, highlighting the importance of facade decoration in urban forms, determining the most preferable way of facade planting that suits the case study, and setting roles for every Stakeholder.

Thus, there should be a clear step to achieve façades planting easily and economically especially in one of the third world countries. To find out how this hypothesis could achieve the research will highlight some studies to focus on the importance of each of plants, and facades.

On the other hand, different ways of facade planting will be addressed as the first step of the comparative analysis (on the cases study) that aims at determining which way of them will be appropriate to the case study as a conclusion, and recommending the application method which would result in more cheerful buildings and 
streets in the poor countries.

\section{Facades and Plantation}

\subsection{Importance of Façades}

Facades commonly defined as the 'face' or outward appearance of a building, facades are typically decorated with ornamental or architectural details that distinguish them from the other sides of the building. The façade thus becomes a key discursive element of any architectural design since it plays a role in how the building itself and its location are to be perceived and experienced. While façades are meant to be designed to communicate a particular message, it is also a text that conglomerates across time and through genres which may include but are often beyond the intent of the architect. In other words, façades are a communicative event that tells stories through its changing materials, that represents the building and its contents and the particular ideologies and power dynamics of the city in relation to its inhabitants and broader economic and political processes as well. (Adam Jaworski, Crispin Thurlow, 2010, p. 256)

In a city designed for pedestrians the floor plan is of a major importance for this is the part of the environment that impinges most upon eye. How often the amateur photographer produces a picture with a large, boring, unadorned foreground; this is the image which is produced on the retina, like the facades along the road, the pavement with its details. The pavements of many continental streets together with the facades bounding them both define external spaces and decorate them to make the users experience a delight. (Cliff Moughtin, Taner Oc, Steven Tiesdell, 1999, p. 19)

\subsection{Importance of Façade Planting}

Urban greening can help dealing with the environmental challenges arising from climate change, such as the global warming. Living walls can be a part of this and offer an aesthetic and architectonical component for making cities more inviting to their inhabitants. One of the key aspects of living walls is that they can enhance the aesthetical value by growing a mixture of different plant species. (Lars Jorgensen, Dorte Dresboll, Kristian Thorup-Kristensen, 2014, p 231)

There are several benefits for living walls; (Susan Loah, 2008, p.1)

- Lowering energy consumption and greenhouse gas emissions.

- $\quad$ Reducing urban heat island effect (UHI).

- Increasing the thermal performance of buildings (lower energy costs).

- Positive effect of hydrology and improving water sensitive urban design (WSUD).

- Improving indoor air quality (IAQ).

- Reducing noise pollution.

- Increasing urban biodiversity and urban food production.

- Improvingt health and well-being.

Another positive side of the visual effect of vertical gardens in landscape design is that the demographic structure in the perception of vertical gardens is an important social phenomenon, where beauty- uniquenessnaturalness- harmonious- call to mind- resting perceptible visual effect- coherence- sustainable- varietycomplexity- colour- form- and texture are appropriate to use in visual studies. People prefer the designs of warm colours and informal lines rather than formal lines and cold colours. (Engin Eroglu, \& Sinem Ozdede, 2014, p. 417)

\subsection{Types of Façade Planting}

\subsubsection{Balconies}

It is surprising how much colours can be created on a balcony, whatever its aspect is. Pots, troughs and hanging-baskets packed with summer-flowering bedding plants are ideal during summer, while from autumn to spring reliance is mainly on small, evergreen shrubs and dwarf conifers. When tender plants are grown, these may have to be taken indoors during winter. (David Squire, 2004, p. 29)

\subsubsection{Living Walls}

Living Walls are also known as Green Walls, Green Facades, Bio Walls or Vertical Vegetation in refer to the vegetation that grows directly onto a building's façade or the vegetation that is grown on a separate structural system that is adjacent to the wall and sometimes attached to it. Vegetation grown in planter boxes and trained on 
a trellis system with mechanized watering is also classified under Living Walls. (Susan Loah, and Yael Stav, 2008, p.6)

Types of living walls: Living walls can be internal or external to the building envelope -as seen in the next figure- and can be broadly classified into three systems:

- Panel system: which normally comprises of pre-planted panels that are brought on site and connected to the structural and the mechanical altering system.

- Felt system: where plants are fitted into felt pockets of growing medium and attached to a waterproofed backing which is then continually moist with water that contains plant nutrients.

- Container and/ or trellis system; where plants grow in containers climb onto trellises. Irrigation drip-lines are usually used in the plant containers to control watering and feeding.

Internal living walls can be built out of any of the above three systems. Some of these walls are specifically integrated with the building's mechanical system. Recycled and fresh air can be supplied to the building's interior through the living wall and thus, the air is cleansed and humidified by plants and growing medium. (Susan Loah, 2008, p. 1)
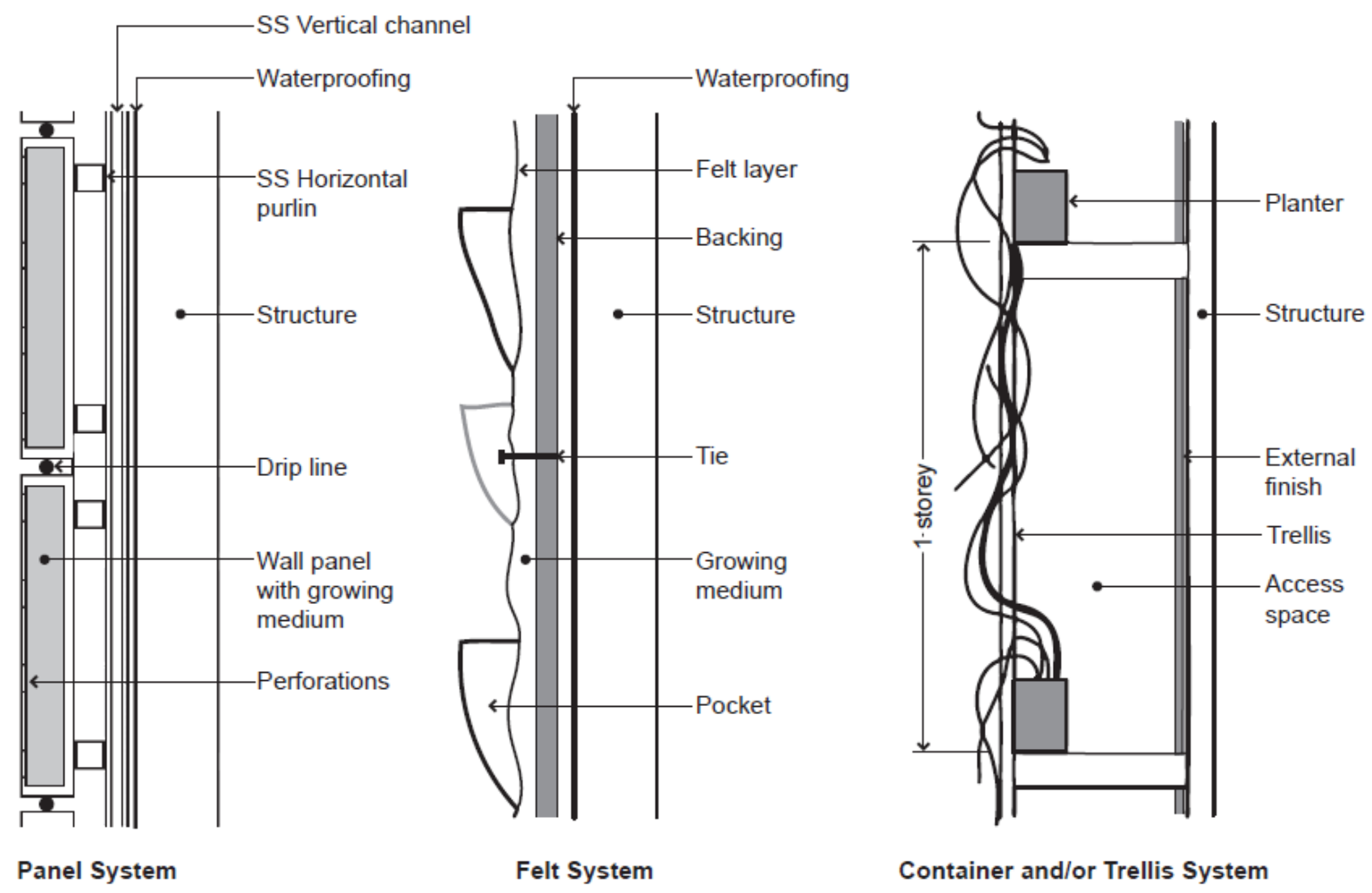

Figure 1. Types of living walls systems

\section{Empirical Study}

\subsection{Study Phase}

The empirical study will target one of the third world countries: Egypt, at one of its new and mid-to high classes districts: New-Cairo, first and fifth settlement because:

- It is a new area that where changes are easily to apply

- The inhabitants are from mid and high social classes.

- Open spaces are clearly seen and any change will be well noticed, which would encourage others to follow the change.

- Beauty is a target for the government, and the apartment owners

- Individual cases already went on planting elevations 


\section{New Cairo City Map}

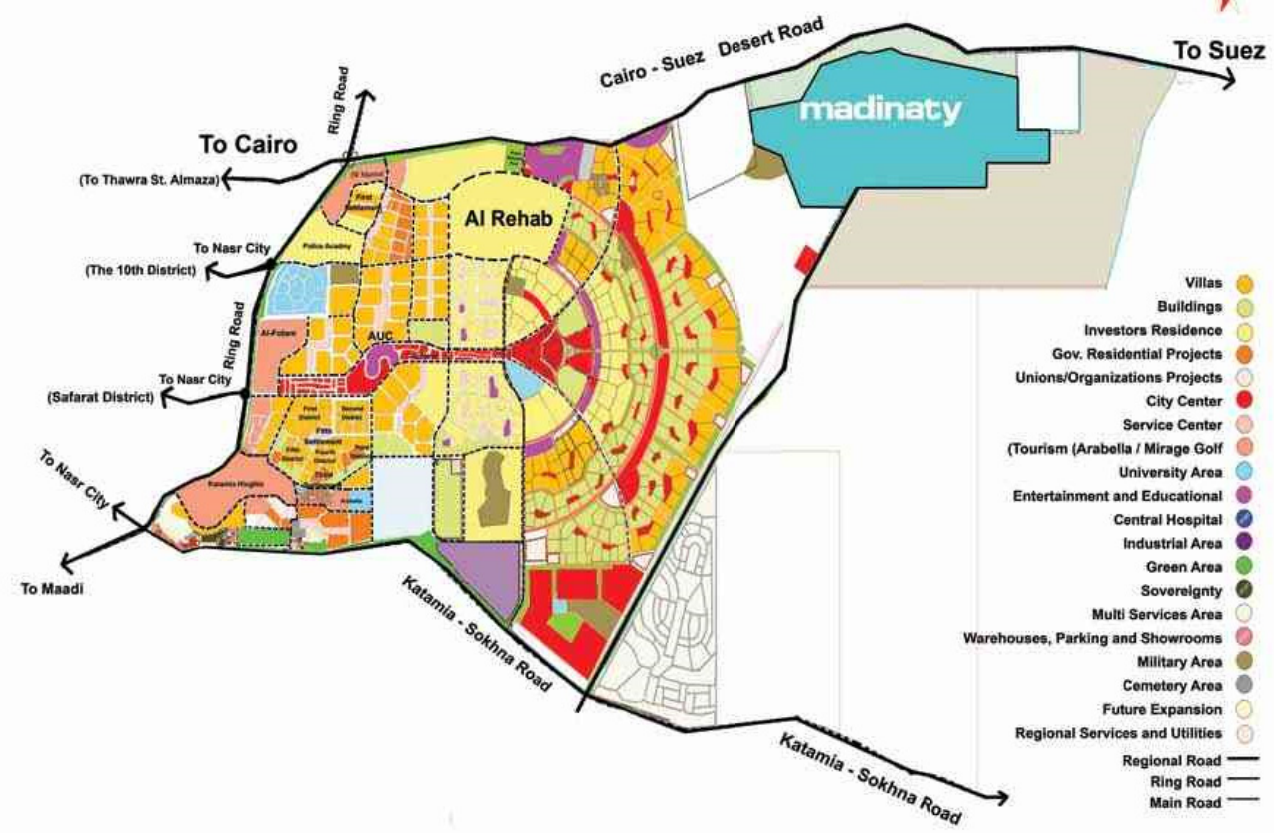

Figure 2. Map of New-Cairo, Egypt

Note: The residential buildings are the common type of buildings in New Cairo.

The following three different types of planting elevations will be under study: balcony planting, living walls, and fence planting. In parallel, different types of buildings will be under study: residential, commercial, and educational buildings. Interviews will be held with stakeholders to fill in questionnaires that contain ten questions targeted to find out which of the three types would be preferable for the community and which of them would be the most effective in contributing a better environment. The answers will be analyzed then results will be extracted.

Example for the first type;

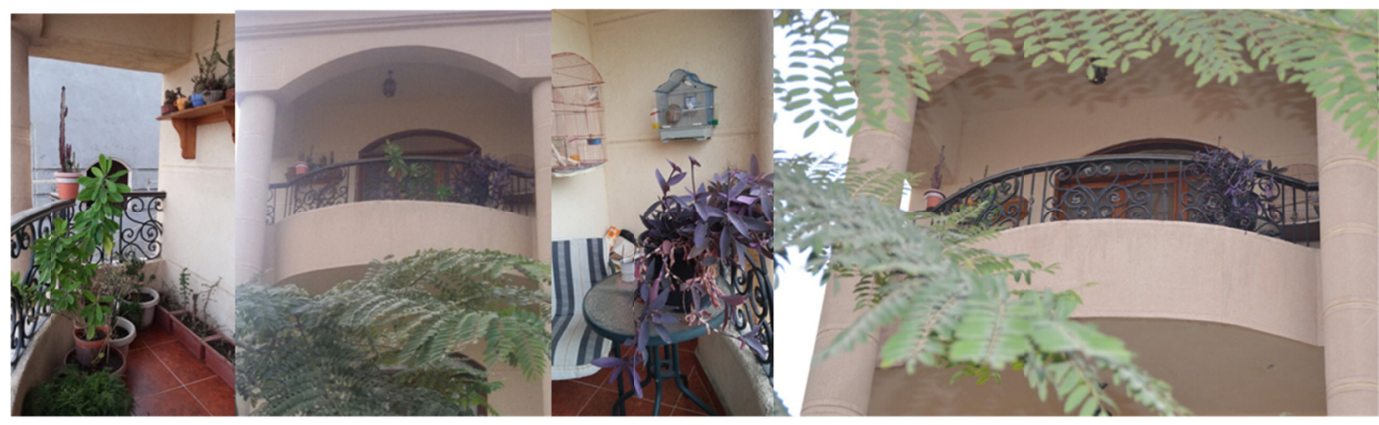

Figure 3. A sample for planting in balconies (residential apartment, first settlement)

Example for the second type; 


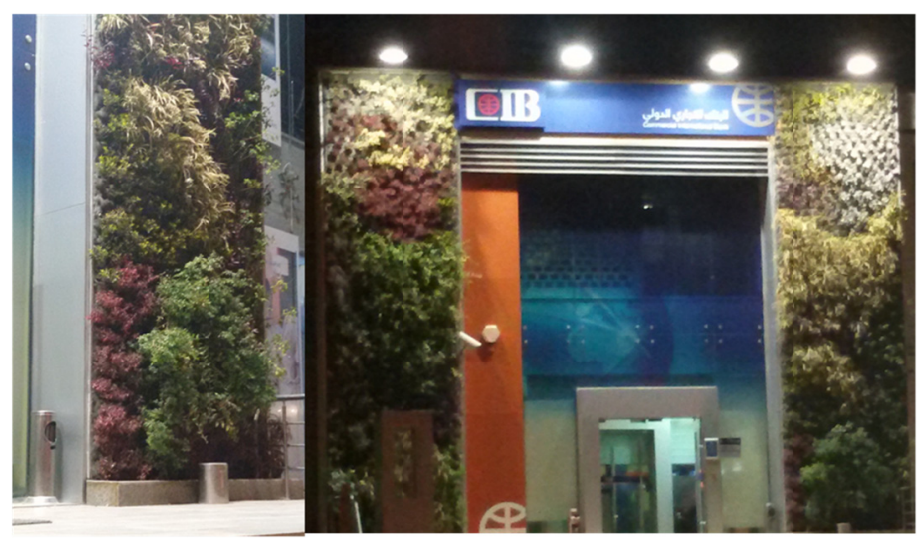

Figure 4. A sample for living walls (commercial building, Bank, fifth settlement)

Example for the third type;

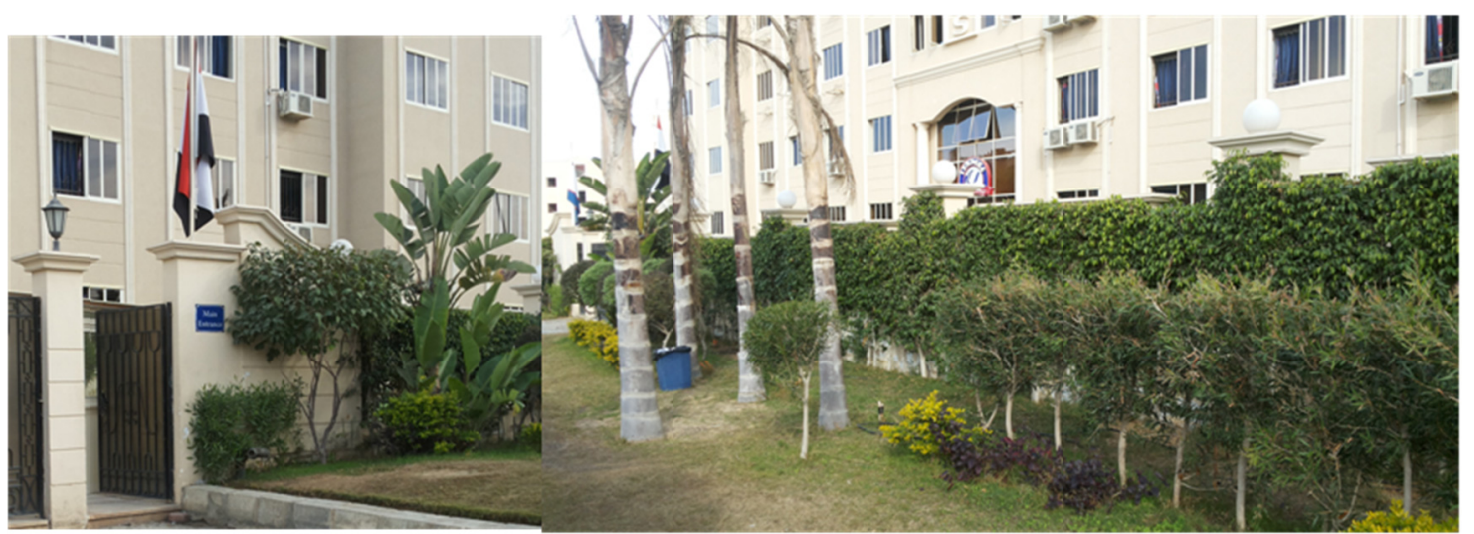

Figure 5. A sample for plating cover fences (educational, school, fifth settlement)

\subsection{Analytical phase}

On this phase questionnaires' answers will be analyzed to extract results

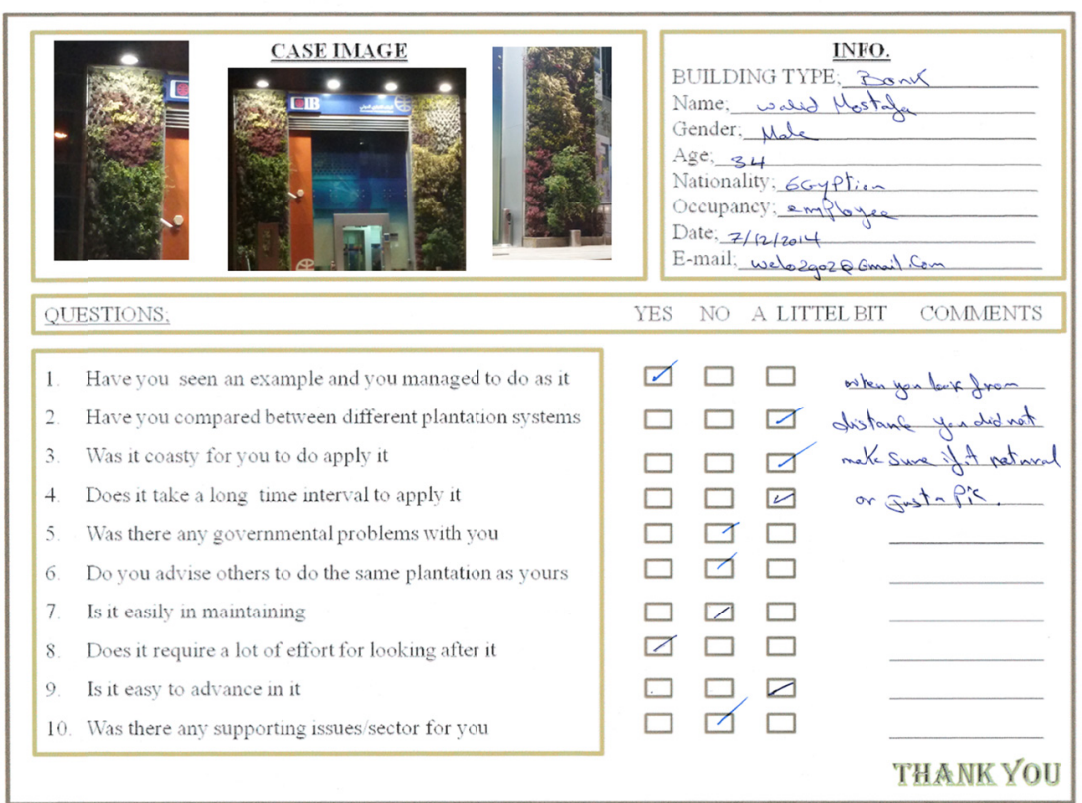

Figure 6. A sample of a questionnaire, living walls, commercial building type 


\section{Results}

A comparative analytical chart will be generated from the filled out questionnaires.

On x-axis: the questions, On y-axis: the answers of the three studied categories.

Line-relation: according to the answers of each questionnaire.

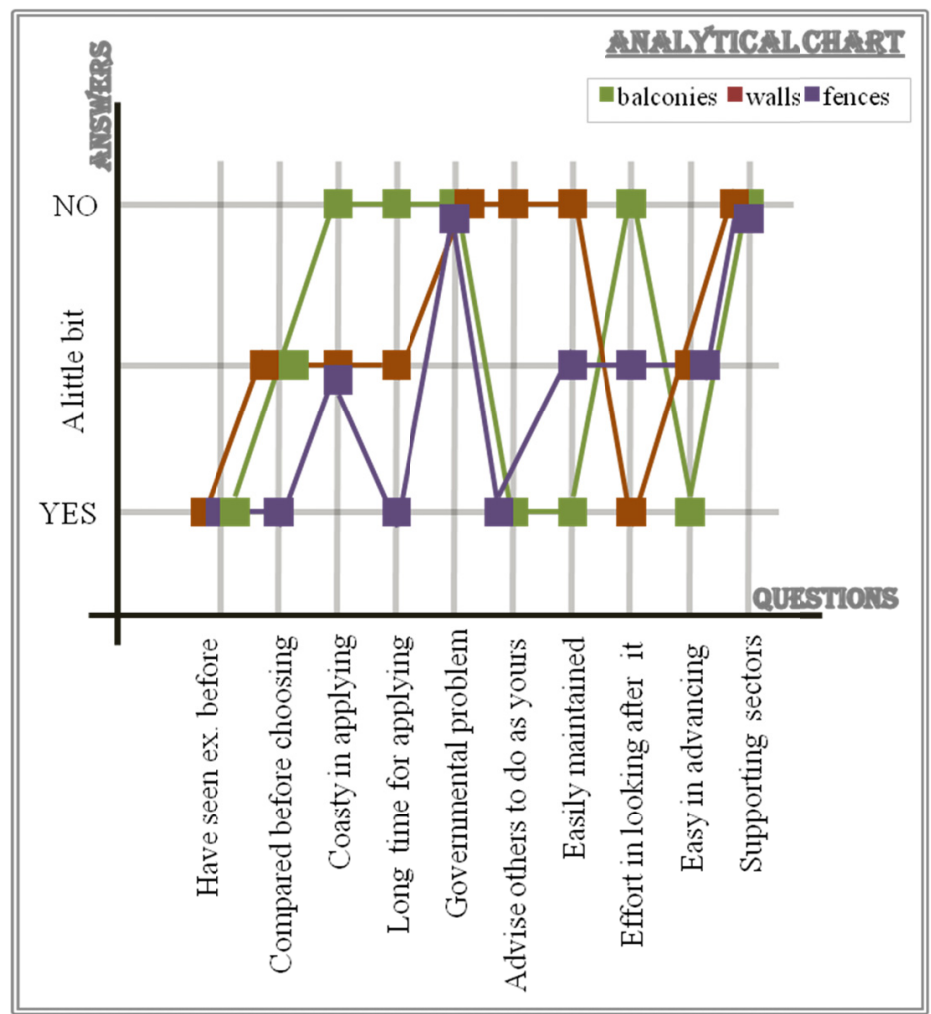

Figure 7. Analytical chart for questionnaires' answers

Carrying out an analytical criteria (comparing different options' contribution to meeting objectives (Dogson, Js. Spackman, M., Perman, A., and Phillips, LD, 2009. p.11)) passes within deveral steps;

- Selecting the field of study.

- Identifying the case-studies.

- Putting technical questions that require answers to achieve the research objectives.

- Listing down comparison criteria from those questions.

- Formulate a matrix between comparison criteria and the three types of studied cases

- Determine the comparison criteria and their judgement method.

- Conclude out what is required from the study.

As per the questions, the comparison criteria field is specified as: stakeholders' experiences, the economic dimension, and time. Each of them has its criterion with different judgement methods e.g. [(yes, no), (hard, moderate, and easy)]. Thus, an analytical matrix is formed (Marco Cinelli, Stuart R. Coles, and Kerry Kirwan, 2014. P.142, 43) between the comparison criteria field (with their criterion), and the three different cases as follows: 
Table 1. Analytical matrix

\begin{tabular}{|c|c|c|c|c|}
\hline $\begin{array}{l}\text { Comparison } \\
\text { criteria field }\end{array}$ & Comparison criteria & $\begin{array}{l}\text { Balcony } \\
\text { Planting }\end{array}$ & Wall Planting & $\begin{array}{l}\text { Fence } \\
\text { Planting }\end{array}$ \\
\hline \multirow{5}{*}{ 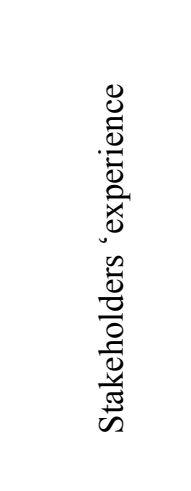 } & $\begin{array}{c}\text { Reviewing similar } \\
\text { examples }\end{array}$ & yes & yes & yes \\
\hline & $\begin{array}{l}\text { Comparing before } \\
\text { determining }\end{array}$ & $\begin{array}{l}\text { Partial: comparing } \\
\text { the kinds of plants } \\
\text { to be used in the } \\
\text { different seasons }\end{array}$ & $\begin{array}{l}\text { Partial: } \\
\text { comparing } \\
\text { systems }\end{array}$ & yes \\
\hline & Governmental problems & no & no & no \\
\hline & Counseling & yes & no & yes \\
\hline & Supporting sectors & No & no & no \\
\hline \multirow{3}{*}{ 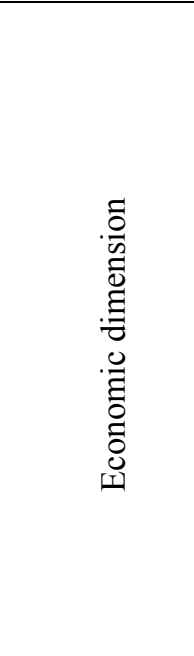 } & Cost & Low & $\begin{array}{c}\text { Partial: according } \\
\text { to the required } \\
\text { area }\end{array}$ & $\begin{array}{c}\text { Partial: according } \\
\text { to the planting } \\
\text { types }\end{array}$ \\
\hline & Maintenance & Easy & hard & $\begin{array}{l}\text { Partial: according } \\
\text { to the area } \\
\text { required to be } \\
\text { maintained }\end{array}$ \\
\hline & Development and changes & Easy & $\begin{array}{c}\text { Partial: as the } \\
\text { system is formed } \\
\text { of units }\end{array}$ & $\begin{array}{l}\text { Partial: as } \\
\text { individual plants } \\
\text { could be easily } \\
\text { taken off and } \\
\text { changed }\end{array}$ \\
\hline \multirow[b]{2}{*}{ 算 } & Planting & Short interval & $\begin{array}{c}\text { Partial; according } \\
\text { to the required } \\
\text { area }\end{array}$ & $\begin{array}{l}\text { Long interval; to } \\
\text { shape plants with } \\
\text { the fence and its } \\
\text { height }\end{array}$ \\
\hline & Maintenance & $\begin{array}{l}\text { Easy and short } \\
\text { interval will be } \\
\text { enough for } \\
\text { maintenance }\end{array}$ & $\begin{array}{c}\text { Hard, and a } \\
\text { specialist will be } \\
\text { needed, which } \\
\text { would require a } \\
\text { long interval of } \\
\text { time }\end{array}$ & $\begin{array}{l}\text { Partial amount of } \\
\text { effort is required } \\
\text { with a need for a } \\
\text { moderate daily } \\
\text { time for } \\
\text { maintenance }\end{array}$ \\
\hline
\end{tabular}

Conclusions;

- Most owners want to see first an example to follow.

- Greens in buildings attract people, which mean that it has a direct and great effect on them.

- Most stakeholders pass through the comparison stage to choose the cheapest, fastest, and easiest.

- Balcony planting is the cheapest way to create green elevations.

- The fastest choice to apply is balcony planting, then fence covering, and then wall covering.

- Government does not play any role (positively/negatively) in arranging plantation in elevations. 
- Stakeholders who plant their balconies and covers their fences advise others to do so, on the other hand, stakeholders who use the wall covering notice that it does not satisfy his need to ask other to do so (the studied case was a Bank, where the employee noticed that clients thought it was an artificial wall - not a naturally green wall-, and no client commented positively on it)

- Eventually, we found that balcony planting is the easiest to maintaining, while the hardest in maintaining is the wall planting.

- $\quad$ Balcony planting is very easy to develop, while the two other kinds are less easy.

- $\quad$ No sectors play any role in greening up facades.

When giving grades to the corresponding answers as an example;

$[1=$ the worst (long time interval, high cost, no support), 5= medium (partially expensive to maintain, and requires relatively long time to apply), and $10=$ the best (easy to maintain, no governmental problems). By referring to the answers in the previous table, we could easily gain a numerical grade, that represents an answer to which system of the three is the best to apply, as well seen in that matrix.

Table 2. Answers in grades

\begin{tabular}{|c|c|c|c|c|}
\hline $\begin{array}{c}\text { Comparison Criteria } \\
\text { Field }\end{array}$ & Comparison criteria & Balcony Planting & Wall Planting & Fence Planting \\
\hline \multirow{6}{*}{$\begin{array}{c}\text { Stake-holders' } \\
\text { experience }\end{array}$} & $\begin{array}{l}\text { Reviewing similar } \\
\text { examples }\end{array}$ & 10 & 10 & 10 \\
\hline & Comparing & 5 & 5 & 10 \\
\hline & Governmental problems & 10 & 10 & 10 \\
\hline & Counseling & 10 & 0 & 10 \\
\hline & Supporting sectors & 0 & 0 & 0 \\
\hline & Cost & 10 & 5 & 5 \\
\hline \multirow[t]{2}{*}{ Economic dimension } & Maintenance & 10 & 0 & 5 \\
\hline & Development and changes & 10 & 5 & 5 \\
\hline \multirow{2}{*}{ Timing } & Planting & 10 & 5 & 1 \\
\hline & Maintenance & 10 & 1 & 5 \\
\hline \multicolumn{2}{|c|}{ TOTAL } & $85 / 100$ & $41 / 100$ & $61 / 100$ \\
\hline
\end{tabular}

Finally, Balcony Planting is the way that suits this study case in order to contribute a better environment.

\section{Discussion}

- $\quad$ There should be a set of two or three examples for the stakeholders to choose [to reach UNITY]; this stage needs to be under the umbrella of a specific sector (government).

- Government should put a clear mechanism to regulate façade/balcony planting (and to monitor violators and take actions with them.

- According to the case study the researcher found that:

a) In the zone of villas, most of the cases have six balconies.

b) According to the interviews, the average cost for planting a balcony is EGP 90 , while the monthly maintenance cost is EGP 15 /balcony

c) According to the interviews, it takes one working day to finish planting two balconies. 
Table 3. Balcony planting estimates

\begin{tabular}{ll}
\hline & Two balconies \\
\hline Time & 1 day \\
Cost & EGP 180 \\
Maintenance Cost (every 2 months) & EGP 30 \\
\hline
\end{tabular}

Note; one villa could be finished in three days

- Identifying this step of balcony planting as a 'project', where the involvement of different actors is required.

- A specific plan with a date to start this project is required. After that, a further strategy is required to apply the same concept at broader levels.

- Interaction between stakeholders should be ongoing, so that they could submit their complaints or even represent new suggestions pertaining to the project.

Contributing to a better environment through façade planting is an easy to achieve primary objective especially after highlighting the importance of plants in our lives, as well as the importance of façade decoration in urban forms, and determining the most preferable planting methods that suit the case study. Setting roles for every member in the community could now be easily done after determining the needed target.

A scheduled time and distribution of fees should be done under the auspices of the government to ensure the stakeholders' commitment to the whole process, of a cost effective quick façade planting, and thus contributing to a better environment.

\section{Acknowledgments}

I am using this opportunity to express my gratitude for my teachers who helped building up my mind. Also, I would like to thank all the study interviewees. Finally, especial thanks go to my family for its support throughout the course of this research.

\section{References}

Cinelli, M., Coles, S., \& Kirwan, K. (2004). Analysis of the potentials of multi criteria decision analysis methods to conduct sustainability assessment, Ecological indicator, Elsevier

Dogson, Js., Spackman, M., Perman, A., \& Phillips, L. D. (2009). Multi-criteria analysis: A manual. Department for communities and local government: London. Retrieved from https://www.gov.uk/government/uploads/system/uploads/attachment_data/file/7612/1132618.pdf

Eroglu, E., \& Ozdede, S. (2014). Visual effects of vertical gardens in landscape. Design: A case study of Duzce University Campus, Duzce University, Duzce/ Turkey.

Jaworski, A., \& Thurlow, C. (2010). Semiotic landscapes: language, image, space. A\&C Black.

Jorgensen, L., Dresboll, D., \& Kristian, K. (2014). Spatial root distribution of plants growing in vertical media for use in living walls. Springer.

Loah, S. (2008). Living walls- a way to green the built environment, BEDP environment design guide, TEC.

Loah, S., \& Stav, Y. (2008). Green a city grows a wall, subtropical cities conference. Retrieved from http://eprints.qut.edu.au/28173/1/c28173.pdf

Moughtin, C., Oc, T., \& Tiesdell, S. (1999). Urban design: ornament and decoration, routledg. Multi-criteria analysis. $\quad$ Retrieved from http://ec.europa.eu/europeaid/evaluation/methodology/examples/too_cri_res_en.pdf

Squire, D. (2004). Small garden specialist -specialist series, New Holland publishers.

Zhou, M. (2013). On interior greening decoration of residence, applied mechanics and materials.

\section{Copyrights}

Copyright for this article is retained by the author(s), with first publication rights granted to the journal.

This is an open-access article distributed under the terms and conditions of the Creative Commons Attribution license (http://creativecommons.org/licenses/by/3.0/). 